\title{
Asymbiotic seed germination and in vitro seedling development of Orchis militaris, an endangered orchid in Siberia
}

\author{
Aleksandra Yurievna Nabieva(D)
}

\begin{abstract}
Background: Terrestrial orchids belonging to the Orchis genus are difficult to propagate and are under great pressure in their natural habitats. Studies regarding the influence of photoperiod and temperature regimes on Orchis militaris germination and morphological changes during immature seed development in vitro are scarce. Our aim was to identify photoperiod, temperature, and different nutrient media requirements for optimization of 0. militaris seed germination and vigorous seedling production.

Results: Post-germination morphological changes were recorded with 0 . militaris seeds collected from 32-day-old fruits, where the percentage of 0 . militaris seeds without embryo was $38.4 \%$. The highest rate of 0 . militaris seed germination (82.6\%) was obtained on Malmgren modified terrestrial orchid medium (mM), enriched by 5\% coconut water, $5 \%$ birch sap, and $0.1 \%$ AC. Nine percent of seedlings were able to reach the advanced seedling stage (stage 6) after 12 months of maintenance on this medium. In all 3 modified media (Harvais, Knudson C and Malmgren), regeneration was via the production of protocorms and seedlings without callus formation. It was proved that more abundantly vigorous protocorms were formed on the modified Harvais 2 under continuous darkness, while the subculture in Knudson C medium with AC addition could be necessary to stimulate their further development. The regeneration success of the species for in vitro conditions was increased by following its natural seasonal cycle.

Conclusion: This study demonstrated an efficient micropropagation system for 0 . militaris using immature seeds and thus widely opened the perspectives for its conservation in nature. The favorable conditions of seed germination periods for in vitro culture, identified as the definite shift of temperatures and photoperiod regimes intrinsic to the species in nature, could improve seedling survival of this medicinally important orchid.
\end{abstract}

Keywords: Orchidaceae, Endangered species, Asymbiotic seed germination, Life cycle, Organic additives

\section{Background}

The genus Orchis Tourn. ex L. (Orchidaceae) includes 21 accepted species and 16 subspecies $[1,2]$. The species belonging to the genus are of great economic importance as their tubers are used to produce a hot beverage called salep, mainly consumed in Greece and Turkey [3]. It contains a nutritious starch-like polysaccharide-glucomannan, which is effective in curing sore throat, digestive problems, diarrhea, and gum disease [4]. The

Correspondence: sibflower05@gmail.com

Department of Biotechnology, Central Siberian Botanical Garden SB RAS, Zolotodolinskya str. 101, Novosibirsk 630090, Russia increasing popularity of traditional, organic food has led to a revival of salep consumption and overharvesting of the plants from the genus Orchis [5]. The species of the genus can be cultivated [6]; nevertheless, many orchids are collected rather from nature [3]. For the protection of rare and endangered orchid species, both in situ and ex situ approaches are important. Tissue culture collections became the most important tools in ex situ conservation of terrestrial orchids [7, 8]. Regardless of the studies conducted toward mass-propagation techniques involving some Orchis species $[9,10]$, tissue culture

Springer Open

(c) The Author(s). 2021 Open Access This article is licensed under a Creative Commons Attribution 4.0 International License, which permits use, sharing, adaptation, distribution and reproduction in any medium or format, as long as you give appropriate credit to the original author(s) and the source, provide a link to the Creative Commons licence, and indicate if changes were made. The images or other third party material in this article are included in the article's Creative Commons licence, unless indicated otherwise in a credit line to the material. If material is not included in the article's Creative Commons licence and your intended use is not permitted by statutory regulation or exceeds the permitted use, you will need to obtain permission directly from the copyright holder. To view a copy of this licence, visit http://creativecommons.org/licenses/by/4.0/. 
system for $O$. militaris propagation in vitro was undeveloped.

Furthermore, data on physiological and morphological aspects of $O$. militaris seed germination and development are scarcely provided, but they are urgently needed to establish in vitro collection and cryopreservation of the species.

We focused on the in vitro germination of the soldier's orchid-Orchis militaris L., a cold-hardy terrestrial Eurosiberian species which has continental distribution, occurring from the Atlantic Coast to as far east as Mongolia [11]. As compared to other mainly subtropical representatives of the genus Orchis, O. militaris demonstrates a loss in total habitat and might be particularly negatively affected by drought because the species occupies the territories with the highest precipitation [12].

This endangered species is included in Annex II of the CITES International Convention and listed in the Red Data Book of the Russian Federation as a rare species found sporadically and in a small population [13]. Smallsized populations, as well as the clusters and groups of individuals that $O$. militaris usually form, might be due to the presence and diffusion of specific fungal symbionts, as suggested by [14].

O. militaris is a summer-winter tuberous perennial polycarpic orchid with spherical tuberoids on short stolons. Usually, two tuberoids can be found on the plant: one developed in the previous year (old tuber), and the second (younger one), developed from the basal part of the stem after flowering, consists of storage materials and a new bud for the next year. Plants consist of a rosette of leaves with a single inflorescence varying from 20 to $45 \mathrm{~cm}$, with a single inflorescence bearing 10-40 hermaphroditic flowers [11]. The species is confined to calcareous soils and occurs more frequently in grazed damp and dry meadows, often among bushes or in light forests and along meadow slopes of mountains [1]. $O$. militaris does not tolerate mowing, cattle trampling, or recreation and under adverse conditions may pass for 38 years into a state of temporary underground rest [15]. In populations $O$. militaris multiplies mainly by seeds, but fruit set tends to be generally lower than $30 \%$ [16, 17]. It is proved that after a seed germinates it takes about 4 years before the orchid leaves appear, and four years more before the plant produces flowers $[11,18]$.

In order to assess the possibility of in vitro propagation of $O$. militaris, effects of basal media plant growth regulators and natural additives on in vitro seed germination, protocorm development, and plantlet formation were studied. The aim of the study was to clarify the development stages of $O$. militaris plants from germination until the formation of new regenerant under the different light and photoperiod regimes. In vitro propagation of $O$. militaris from seeds should be considered as part of an integrated conservation program aimed at safeguarding the species from extirpation in the wild.

\section{Methods \\ Orchid seed source}

O. militaris immature seeds were collected from naturally pollinated plants approximately 32 days after anthesis in 2019 in the Novosibirsk Region (NR), Russia. When pollination occurred, the flower became wilting, and the days after pollination was accounted. O. militaris immature fruits were immediately used or stored in a light thermostat (Rumed, Germany) under a 16-h photoperiod with a light intensity of $20 \mu \mathrm{mol} \mathrm{m} \mathrm{m}^{-2} \mathrm{~s}^{-1}$ and a temperature of $7{ }^{\circ} \mathrm{C}$ for 1 day before the inoculation in vitro. Selecting the green capsules is widely used methodology for the successful germination in vitro for many terrestrial orchids, which mature seeds exhibited dormancy-related germination issues [19]. It was shown that their low percentage germination is attributed to high ABA levels and formation of a thick carapace with phenolic deposits during seed maturation [20]. The cenopopulation is located at 190 m elevation; N 54027 '42' '; E 83020'42' '. Identification of species was done according to [21]. The territory, where O. militaris cenopopulation was found, belongs to the forest-steppe region of West Siberia. It occurred in post-forest successional meadow with scattered birch trees at the edge of the birch forest. Co-growing plant species at this location were represented by Filipendula vulgaris Moench. Aegopodium podagraria L., Euphorbia virgata Waldst. Et Kit., Plantago maxima Juss. ex Jacq., Sanguisorba officinalis L., Phlomis tuberosa L., Pedicularis resupinata L., Galium boreale L., G. verum L., Medicago falcata L., Vicia cracca L., Cypripedium macranthon SW., Epipactis palustris (L.) Crantz, E. helleborine (L.) Crantz, Anemone sylvestris L., Ranunculus acris L., and Thalictrum simplex L.

\section{Asymbiotic seed germination}

The present research was conducted to study the $O$. militaris asymbiotic seed germination and seedling development under the influence of photoperiod, medium composition, and hormone treatments. Green undehisced capsules of $O$. militaris were collected from the medium part of each specimen's inflorescence, washed under running tap water for $30 \mathrm{~min}$, and submerged in a mixture of 2 drops of Tween-20 and 20\% Domestos, a commercial detergent, for $10 \mathrm{~min}$. Three replicates, each consisting of about 100 seeds, were counted. Thereafter, under aseptic conditions, capsules were treated with $0.25 \%$ mercuric chloride $(\mathrm{w} / \mathrm{v})$ for $8 \mathrm{~min}$, then with $70 \%$ ethyl alcohol for $30 \mathrm{~s}$, and flamed. Finally, fruits were rinsed 3 times with sterilized distilled water. The seeds were scooped out from the capsules and small masses of 
the aggregated seeds. The seeds from each capsule were equally distributed in $75 \times 120 \mathrm{~mm}$ Petri dishes $(\sim 200$ seeds/plate) containing $20 \mathrm{ml}$ of 3 variants of sowing medium. Three replicate dishes were prepared for each accession of seeds. These initial media were based on a modified formula of Harvais [22] with or without addition of growth regulators (PGRs): (1) modified Harvais without PGRs-mHar0; (2) modified Harvais with $4.92 \mu \mathrm{M} 2 \mathrm{iP}+1.61 \mu \mathrm{M}$ IBA-mHar2; (3) modified Harvais with $4.44 \mu \mathrm{M} \mathrm{BA}+1.61 \mu \mathrm{M}$ IBA-mHar3. The original medium was modified as follows: agar was reduced from 10 to $6 \mathrm{~g} \mathrm{l}^{-1}$, and $10 \mathrm{~g} \mathrm{l}^{-1}$ of sucrose was added. The addition of $100 \mathrm{~g} \mathrm{l}^{-1}$ potato homogenate $(\mathrm{PH})$ was implemented according to original receipt of Harvais medium. Percentages of germinated seeds inoculated onto 3 media variants: mHar0, mHar2, and mHar3 and cultured under $0 / 24 \mathrm{~h} \mathrm{~L} / \mathrm{D}$ were counted in comparison with those cultured on the same media under 16/8 h L/ D photoperiod (mHar0", mHar2", and mHar3"). For $O$. militaris, seed viability determination (the ratio of empty seeds to seeds with embryos) was calculated under stereo microscope in 10 different sights of view of each seed lot taken in experiment.

Germination was recorded based on the number of full seeds, discounting seeds without embryos. Early seedling development was recorded up to a maximum of 16 months. Germinated seeds were counted monthly after sowing until germination by using stereo microscope (Stereo Discovery V 12, Carl Zeiss, Germany). The percentage of protocorms and seedlings in a developmental stage was calculated by dividing the number of seeds at that stage by the total number of germinated seeds. At the beginning of each cultivation period (Fig. 1), cultures were observed to determine the time of germination at 1 -month and to reveal the appearance of protocorm developmental stages at 2-month intervals.

Seeds and developing protocorms were identified and assigned to one of developmental stages accordingly to study the development of seeds of other terrestrial orchids [23], where the stage 6 was added, which was distinguished by having two expanded leaves (Table 1). Seeds at stages 1 and 2 are considered not germinated. Germination (stage 3) indicated the emergence of the full embryo from the testa (Table 1).

After germination at different photoperiods (Fig. $1\left(\mathrm{~A}_{1}\right.$, $\left.\mathrm{A}_{2}\right)$ ), all protocorms reaching $2 \mathrm{~mm}$ in size were transferred in 150-ml culture glass jars on Knudson C medium [24] without PGRs, modified by supplementing with $0.1 \%$ AC (mKC), for 2 months under cool white fluorescent light (Philips, Pila, Poland) at an intensity of $32 \mu \mathrm{mol} \mathrm{s}^{-1} \mathrm{~m}^{-2}$ with 16/8 h L/D photoperiod (Fig. 1B). For subsequent development, protocorms and seedlings were maintained for 13 months on 6 different hormonefree growing media: (1) $\mathrm{mKC}$; (2) $\mathrm{mKC}$ with organic additives $(\mathrm{OA})=\mathrm{mKC}+\mathrm{OA}$; (3) double modified Harvais medium-DmHar; (4) DmHar with $\mathrm{OA}=\mathrm{DmHar}+\mathrm{OA}$; (5) Malmgren [25] modified medium (mM); (6) $\mathrm{mM}$ with $\mathrm{OA}=\mathrm{mM}+\mathrm{OA}$. The $\mathrm{KC}$ and $\mathrm{M}$ media modification consisted in the addition of the same contributions of micronutrients, vitamins, sucrose, and agar identical to the modified Harvais medium (mHar), as outlined above. A double modification of mHar medium was in the replacement of $100 \mathrm{~g} \mathrm{l}^{-1} \mathrm{PH}$ by the combination of OA: $5 \%$ coconut water $(\mathrm{CW})$ and $5 \%$ birch sap (BS). All initial and growing media were adjusted to $\mathrm{pH} 5.8$ before autoclaving.

The protocorms with meristematic center were maintained in the dark conditions at $4{ }^{\circ} \mathrm{C}$ for 3 months (Fig. $1 C$ ). During this period, the effects of cytokinin (BA or 2iP) applied with IBA and one of 2 illumination regimes on germination and protocorm growth were evaluated.

After leaf primordium generation, we applied 16photoperiod during 4 months in combination with $23 \pm$ $2{ }^{\circ} \mathrm{C}$ until the first leaf was formed (Fig. 1D) or the second one occurred (Fig. 1F). In the course of 16 months of the experiment, O. militaris seedlings were subjected

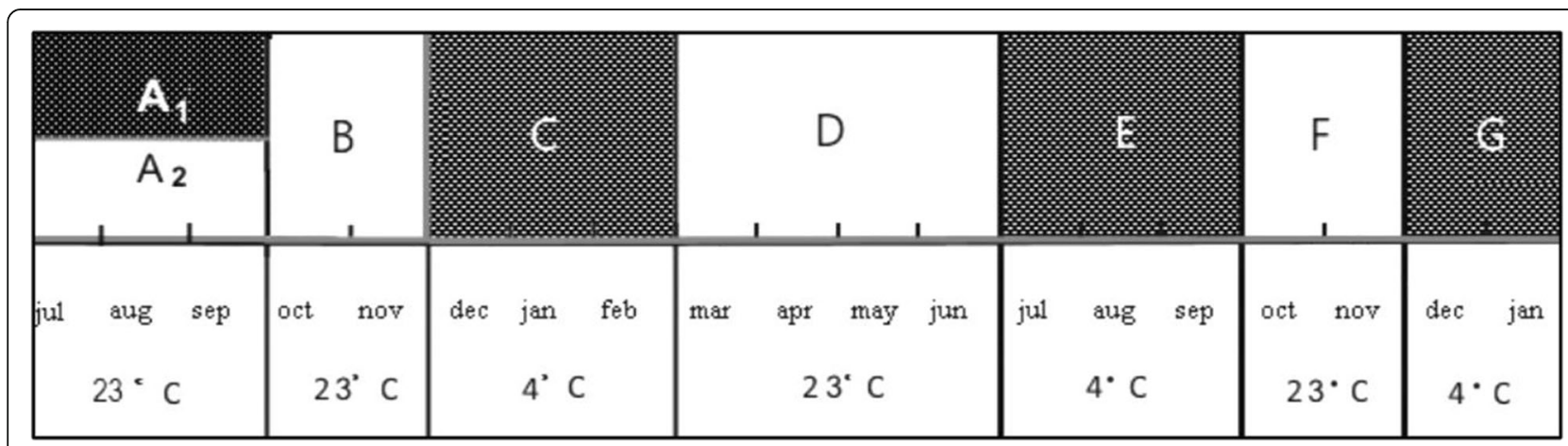

Fig. 1 Scheme of experimental timing (July 2019-January 2021) followed in the study of O. militaris seedlings arising from immature seeds. \# From the top to the foot of the dark and white rectangles (denoting dark and light conditions, applied during the periods of the orchid seed germination, marked as $\left.\mathrm{A}_{1}, \mathrm{~A}_{2}, \mathrm{~B}, \mathrm{C}, \mathrm{D}, \mathrm{E}, \mathrm{F}, \mathrm{G}\right)$ are indicated: timing of the seed cultures (months); temperature conditions $\left({ }^{\circ} \mathrm{C}\right.$ ) 
Table 1 Description of developmental stages during orchid seeds germination, according [23] with some alterations concerning stage 2 (marked $^{*}$ )

\begin{tabular}{ll}
\hline Stage & Description \\
\hline Stage 1 & Unimbibed seed with intact testa \\
Stage $2^{*}$ & Swelling of embryo and its enlargement followed by splitting of testa \\
Stage $3^{1}$ & Protocorm arising, when rupture of testa occurred and first rhizoids developed \\
Stage $4^{1}$ & Enlargement of protocorm and formation of protomeristem \\
Stage $5^{1,2}$ & Further enlargement and development of first green leaf \\
Stage $6^{1,2}$ & Emission of second green leaf \\
\hline
\end{tabular}

$\#^{1}$ Stages considered as germinated; ${ }^{2}$ photosynthetic stages

to 3 dormant periods (Fig. 1C, E, G) (maintenance at 4 ${ }^{\circ} \mathrm{C}$ in dark conditions), alternated with 3 growing periods under $16 \mathrm{~h}$ /day light at $23 \pm 2{ }^{\circ} \mathrm{C}$ (Fig. 1B, D, F). This $O$. militaris seed-protocorm-seedling growth cycle supported in vitro was similar to the natural life cycle of the species $[11,18]$.

Mean germination values (percentage of germinated seeds) were calculated by dividing the number of seeds at stage 3 by the total number of seeds with embryos. After 3 months of culture, the protocorm formation frequency was also calculated as the percentage of the number of protocorms with promeristem among the total germinated seeds; this value was also showing the amount of germinated seeds giving plantlets.

Each treatment had 3 replicates and was conducted three times. One-way analysis of variance (ANOVA) in STATISTICA 8 software (StatSoft Inc., Tulsa, OK) was used for statistical analysis. Seed germination and viability data were given as mean \pm standard error (SE). Means were compared using Duncan's Multiple Range Test (DMRT) at a significance level of $p<0.05$.

\section{Results}

In the study, propagation of $O$. militaris from seeds has been achieved through the use of fruits collected at 32 days after anthesis, which were green and un-dehisced. Immature seeds of $O$. militaris had light brown, nearly colorless testa (Fig. 5A) in contrast to mature seeds (60 days after anthesis), which have a dark brown, translucent one (Fig. 5B). There was no significant difference in the percentage of aborted $O$. militaris seeds counted for immature and for mature ones: $38.4 \pm 2.5$ and $40.0 \pm$ 3.7 , respectively.

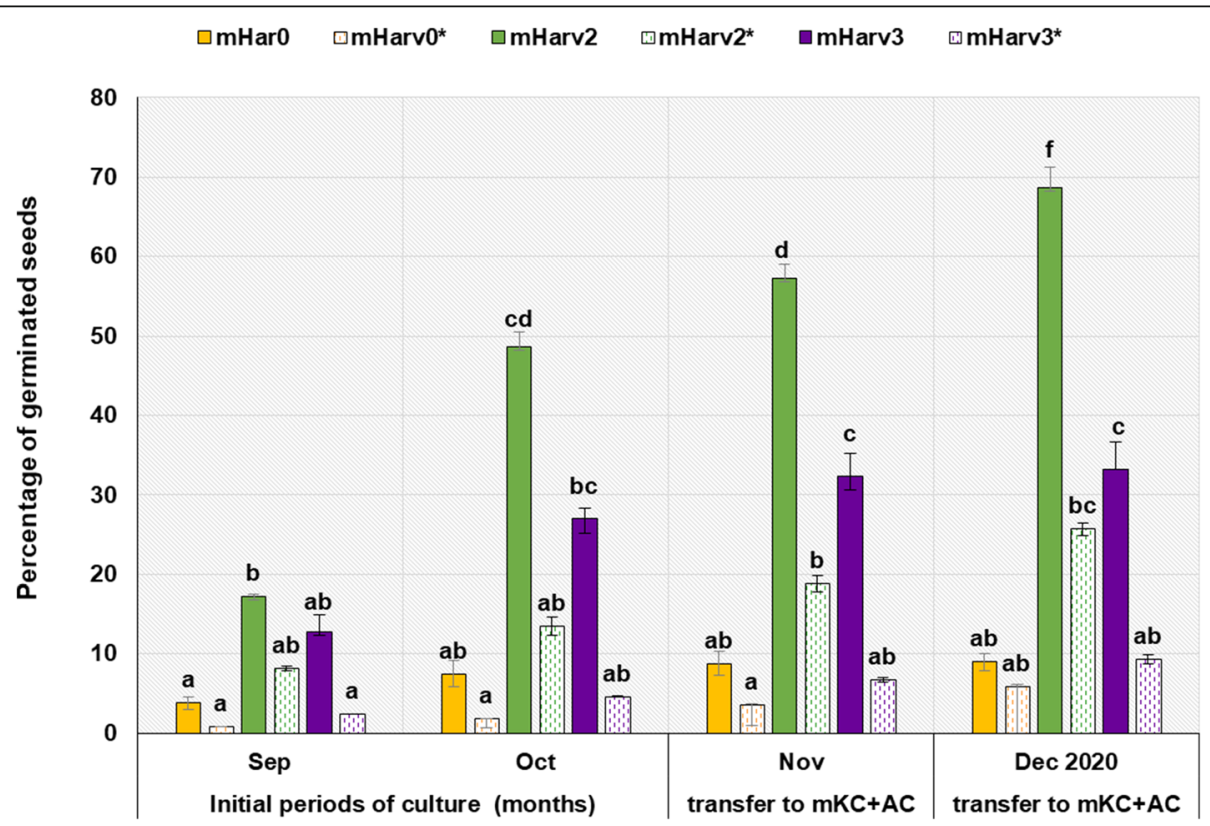

Fig. 2 Comparative effects of plant growth regulators and photoperiod on the germination of immature seeds of Orchis militaris during 5 months of cultivation. \# ${ }^{*}$ mark is the indication of the $16 / 8 \mathrm{~h} \mathrm{L/D} \mathrm{photoperiod} \mathrm{conditions,} \mathrm{in} \mathrm{which} \mathrm{seed} \mathrm{cultivation} \mathrm{on} \mathrm{these} \mathrm{media} \mathrm{was}$ performed, in contrast to the dark conditions $(0 / 24 \mathrm{~h} \mathrm{L/D)}$ ), applied with the media without this mark; the means having the same superscript letters in a column were not significantly different as determined by Duncan's multiple range test $(p<0.05)$ 
It was observed that $O$. militaris immature seeds were capable of germinating on all media tested regardless of illumination regime, but the rate of protocorms and seedlings development depended largely on the presence of definite cytokinin type and applied photoperiod (Fig. 2). All PGRs treatments under 2 photoperiod regimes, assayed for inducing asymbiotic $O$. militaris seed germination, generated the highest amount of protocormes. Only minimal germination was observed with the seeds cultivated on mHar0 medium without PGRs (less than $10 \%$ ), whereas BA and 2iP application led to a significant increase in protocorm formation $(27.0 \%$ and $48.6 \%$, respectively). The continuous darkness (Fig. $1\left(\mathrm{~A}_{1}\right)$ ) and $2 \mathrm{iP}$ mediated medium (mHar2) both resulted in a significantly higher number of protocorms (Fig. 2).

Subsequent transplantation was performed according to embryo growth rate and the stage of protocorm development. The most numerous protocorms, which reached stage 4 during maintenance on $\mathrm{mKC}$ with $\mathrm{AC}$ addition $(68.7 \pm 2.6 \%)$, were those originated from immature seeds, inoculated on mHar2 medium (Fig. 2). Most appropriate for transplanting were protocorms which had produced a leaf primordium (stage 4) and reached $2-3 \mathrm{~mm} \varnothing$. For subsequent cultivation, only these protocorms transferred from mHar2 medium were used. When cultivated at $23 \pm 2{ }^{\circ} \mathrm{C}$ on the media except mKC, supplemented with $0.1 \% \mathrm{AC}$, protocorms stopped growing in size, and browning of the medium was observed. Thus, intermediate period for 2 months of protocorm maintenance on mKC medium without PGRs but with $0.1 \%$ AC added was necessary to produce viable protocorms.

In order to examine the effect of culture media for the successful protocorm and seedling development in the second part of the experiment, the efficiency of 6 growth media with or without organic additives (CW and BS) were tested. All media affected protocorm development differently: the highest protocorm development percentage was obtained on $\mathrm{mM}+\mathrm{OA}$ medium (82.6\%), followed by DmHar + OA (59.4\%) and by $\mathrm{mKC}+\mathrm{OA}$ (38.3\%) (Fig. 4). The addition of organic compounds ( $\mathrm{CW}$ and $\mathrm{BS}$ ) to $\mathrm{mM}$ medium continued to have a higher number of protocorms and seedlings, which produced first secondary roots and true leaves (stage 6, Fig. 3; Fig. 4). Only protocorms firstly appeared on mHarv2 under continuous darkness and further maintained on $\mathrm{mKC}+\mathrm{AC}$ and on $\mathrm{mM}+\mathrm{OA}$ media were able to reach the advanced seedling stage (stage 6) within 16 months of culture (Fig. 3).

MM medium, supplemented with the organic compounds (CW and BS) showed the highest efficiency for protocorm formation (in comparison with other media with the same additives (Fig. 4). When protocorms (2 $\mathrm{mm}$ and more in $\varnothing$ ) were transferred for cultivation on the growing media, which were not supplemented with $\mathrm{OA}$, advanced seedling maintenance was not achieved, protocorm and plantlet development finally failed. The data obtained indicate the beneficial effect of organic

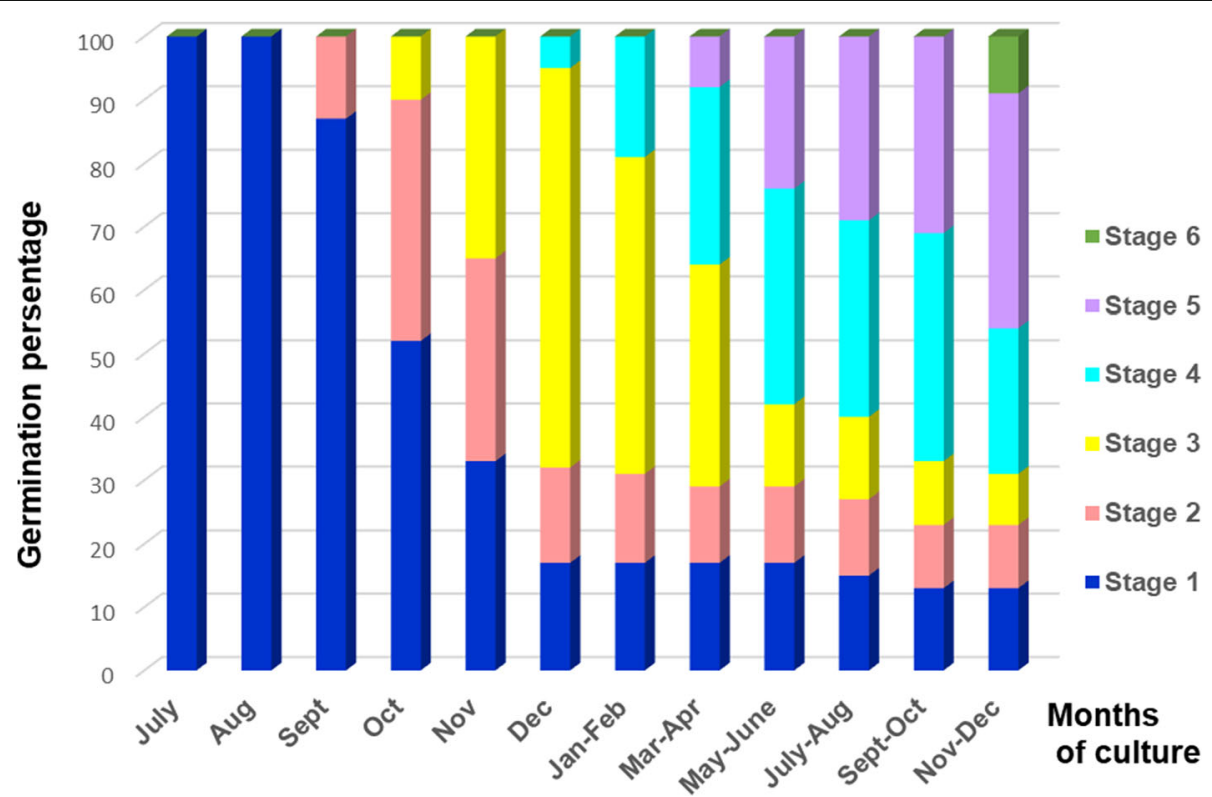

Fig. 3 Germination percentage during different stages of Orchis militaris seed development scored monthly on mHar2 and mKC + AC media and 2-monthly on $\mathrm{mM}+\mathrm{OA}$ medium 


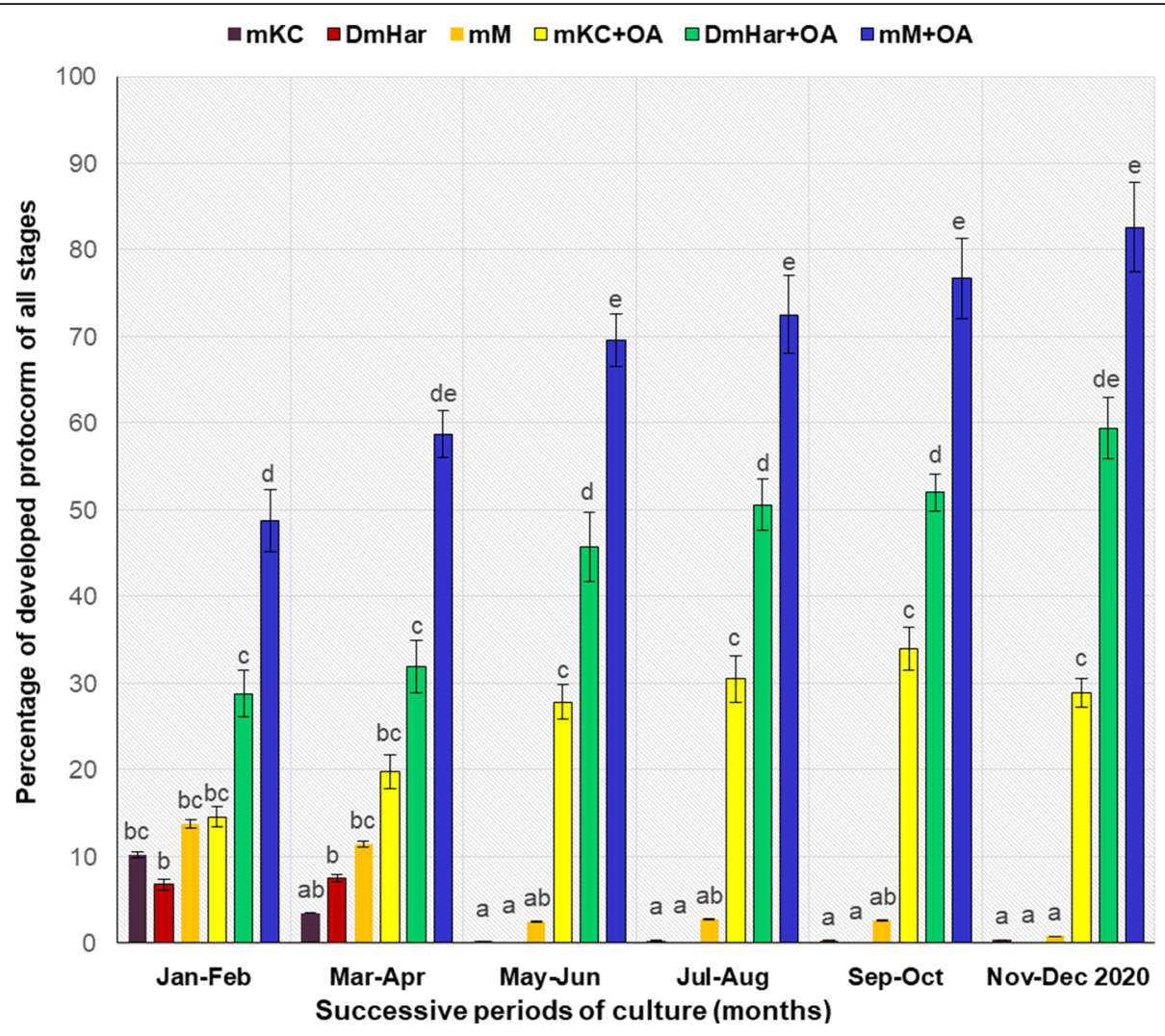

Fig. 4 Effects of growing medium composition and organic additives on Orchis militaris protocorm formation. \# Means having the same superscript letters in a column were not significantly different by Duncan's multiple range test $(p<0.05)$

additives including CW and birch phloem sap, which enhanced the appearance of $O$. militaris seedlings from protocorms.

The seeds sown on July 14 started to germinate in mid-October. The first stage of germination was the imbibition of water by the seed, which led to omnidirectional embryo enlargement. Initially the embryos became white, and globular embryo was formed (Fig. $5 \mathrm{~B})$. The globular stage subsequently developed into the swelling stage; the first protocorms appeared after 2 months of O. militaris seeds inoculation (Fig. 5C). The early phase of protocorm formation commenced with the appearance of the apical meristem dome and the few translucent rhizoids (Fig. 5C, E). The protocorm formation depends on the type of culture medium used. In our study, the highest rate of protocorm and seedling formation in O. militaris was obtained on Malmgren modified terrestrial orchid medium (82.4\%).

Longitudinal growth at the chalazal pole followed, as in other terrestrial orchid species [26], and the apical dome subsided into the body of the protocorm (Fig. 5D). Protocorms of O. militaris exhibited a phase of conical meristematic dome growth without the production of photosynthetic leaf primordia (Fig. 5G, I). This phase (Fig. 5J) is also characterized by prolific rhizoid production. The stage of seedling began when the first leaf appeared and a stem developed (Fig. 5K), and plantlets were then suitable to move into light; after that, the apical dome turned green within 2-3 weeks (Fig. 5L). The development of protocorms into plantlets was normal (without callus formation).

True leaves and roots were observed 14-15 months after germination, but root initiation on all media was yet limited, and a maximum of $24.5 \%$ was recorded for $O$. militaris seedlings cultured on $\mathrm{mM}+\mathrm{OA}$ media. The advanced O. militaris seedling stage (Fig. 5M, N, O) was distinguished by multiple leaves and roots development. Nine percent of plantlets, which have $4.0-6.5 \mathrm{~cm}$ long shoots and roots, formed when the second leaves appeared after the additional 2-month cold treatment (4 $\left.{ }^{\circ} \mathrm{C}\right)$, were appropriate for transplanting into soil after 16 months from the inoculation (Fig. 5O).

The most suitable way to obtain $O$. militaris seedlings reaching stage 6 of development appeared to be seed incubation for 3 months on mHar2 medium with $4.92 \mu \mathrm{M}$ $2 \mathrm{iP}+1.61 \mu \mathrm{M}$ IBA, followed by 2 -month maintenance on $\mathrm{mKC}$ with $\mathrm{AC}$ addition and subsequent cultivation on $\mathrm{mM}+\mathrm{OA}$ medium without PGRs throughout shifting temperature and photoperiod regimes, according to the lifespan of the species (Figs. 1 and 3). Moreover, it 

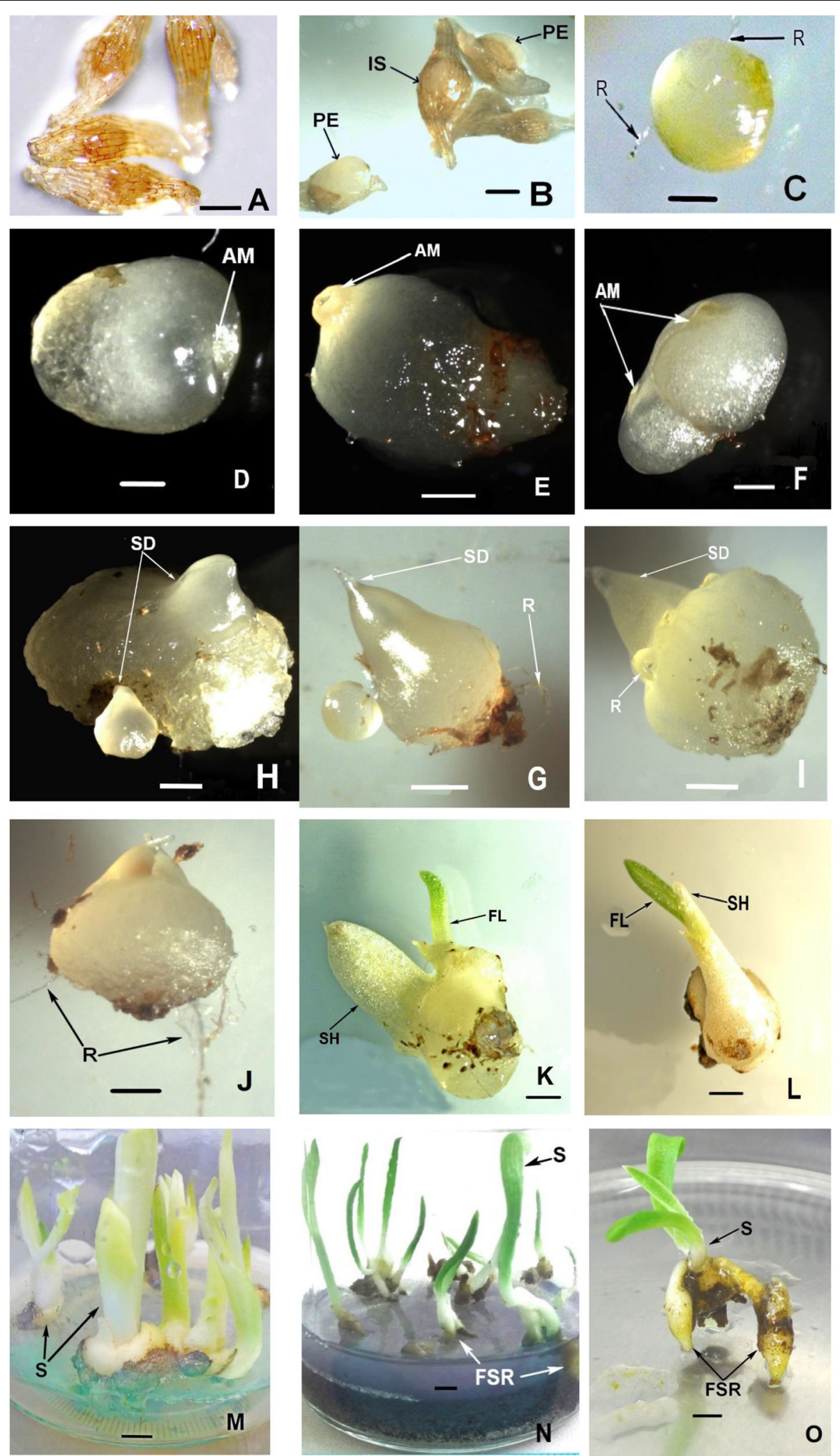

Fig. 5 (See legend on next page.) 


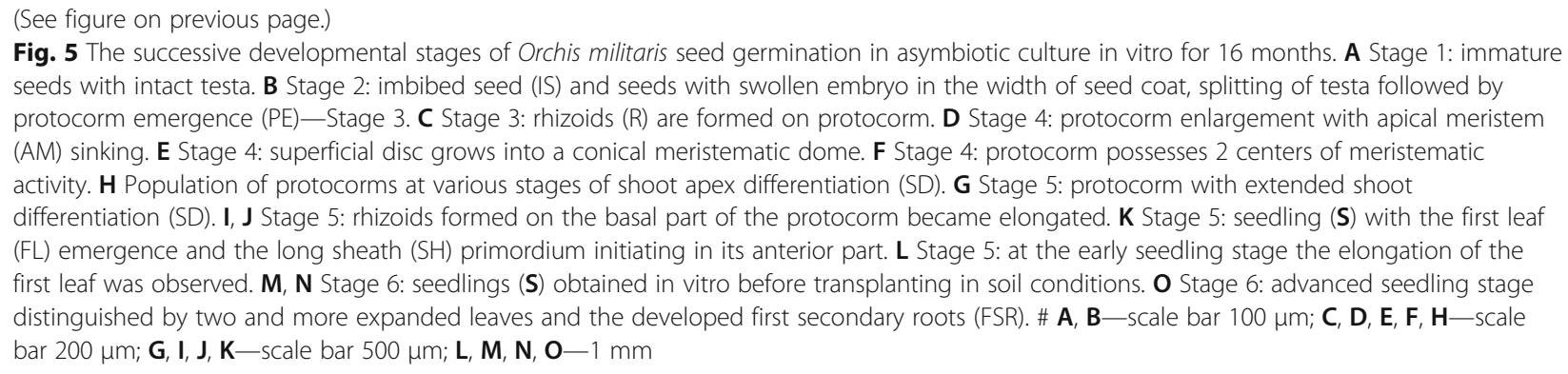

was noted that despite showing early signs of germination, light-incubated seeds were unable to develop into seedlings.

\section{Discussion}

Orchis species have been found to be more troublesome [27], in contrast with the easily in vitro propagated genera like Dactylorhiza. Researchers have observed low levels of $O$. militaris mature seed germination, especially during the first $7-8$ months $[28,29]$. In our study, the percentage of aborted O. militaris seeds (38.4\%) was quite similar to the measurement carried out by [30] for naturally pollinated specimen (45.6\%). The relatively low level of potentially competent (viable) seeds in comparison with rewarding species appears to be an intrinsic feature of the deceptive orchids like $O$. militaris, since they have no pollinator abundance [31].

It was demonstrated previously that selecting "green" capsules at a certain time of their development increases the rate of asymbiotic seed germination [32]. Thus, immature orchid seeds which have underdeveloped and permeable testa were successfully used as source material for our work.

Our previous results showed that the cultivation of $O$. militaris protocorms under the constant physical conditions on the same medium was unsuccessful: most protocorms stopped their growth at the early stage of swelled embryos (data not shown). These findings are in concordance with the data obtained by [33], showing that the regeneration success of orchids for in vitro conditions could be increased by following their natural seasonal cycle, where temperature and light changes are the significant requirements. Baskin et al. [34] recommended alternating temperatures during germination, as constant temperatures are not common in nature. During the life cycle in nature, early flowering Orchis species require 26 months' dormancy period to generate basal leaves [11, $18,35]$. In this study, we attentively followed the $O$. militaris dormancy periods inherent in the orchid with a lifespan of 16 months, and thus observed the emergence of new developmental stages of seed germination just after the dormancy period was over. Similar data were reported for Mediterranean species Orchis patens, whose protocorms and seedlings were not able to grow successfully under invariably warm or cold conditions [36].

In our study, germination of $O$. militaris immature seeds occurred regardless of photoperiod or media treatments; however, stage 6 , which reflects advanced protocorm to seedling development, was exhibited only by the seeds initially incubated in the dark. Numerous studies showed that seed germination in many temperate terrestrial orchids is inhibited by light incubation [37, 38]. According to [39], the inhibition of germination of Cephalanthera falcate immature seeds was also endured by illumination. In this work, O. militaris seeds subjected to total darkness germinated more vigorously than those incubated in the light, as opposed to the findings of $[9,10]$, where the best photoperiod regime for germination of some Orchis species was indicated as 16/8 light/dark. This may suggest the lower light requirement for O. militaris immature seeds germination, in comparison with the Orchis species germinated by mature seeds.

This study provides evidence of the widely supported fact that the medium composition, where the mineral salt concentration has been reduced and organic compounds increased, had an important role in orchid seed germination and protocorm development [40]. Malmgren [25] reported on the benefits of reduced inorganic salts in the new basal medium, where organic additive such as $\mathrm{PH}$ was introduced. Similar to these data, the current study proved that the seeds of $O$. militaris germinate successfully in the presence of organic additives, in particular $\mathrm{PH}, \mathrm{CW}$, and BS. The selection of these OA was inspired by the results of [41], who showed that in the absence of CW, BS, or PH [42] the protocorm development was not observed in the course of Cypripedium seed germination. Based on the results of [43], who successfully applied $\mathrm{PH}$ in combination with $\mathrm{CW}$ for enhancement of Cymbidium findlaysonianum plantlet formation, we used only $\mathrm{PH}$ for initial germination of $O$. militaris seeds, while CW in combination with BS were applied for protocorm and seedling maintenance.

Organic supplements provide a natural source of carbohydrates, inorganic ions, amino acids, vitamins, and phytohormones, promoting growth and morphogenesis 
in orchid seed cultures. CW is known to support cell division in the tissue culture of orchids for its zeatin and zeatin ribosides content [44], whereas auxin and gibberellin-like constituents, found in BS [45], as well as carbohydrates and amino acids intrinsic to $\mathrm{PH}$ [46], commonly facilitate seed germination and enhanced seedling growth of tropical [47] and temperate [48] orchid species.

In many reports, PGRs proved to be effective in enhancing immature orchid seed germination: cytokinins promoted cell division of developing embryos [19], while auxins influenced leaf formation and protocorm morphogenesis [49]. Our observations showed that in the mHar0 treatment, excluding PGRs, nearly all protocorms stopped their growth at early developmental stages and this is in agreement with the results of [50], who obtained that protocorms were larger after two months of growth on the medium with $10 \mathrm{mg} / \mathrm{l}$ cytokinin, compared to other variants of germination study. The enhanced formation of $O$. militaris protocorms, growing to over $2 \mathrm{~mm}$ in height during 3 months, occurred at $23 \pm 2{ }^{\circ} \mathrm{C}$ in darkness with the most effect of combination of $2 \mathrm{iP}$ and IBA treatment (in concentrations of $4.92 \mu \mathrm{M}$ and $1.61 \mu \mathrm{M}$, respectively). The combination of these factors reflects the complexity of specific requirements for in vitro seed germination, which appeared to be unique for any orchid species. This advantage of the PGRs inclusion in basal medium is in agreement with the results of studies indicating that a combination of auxin and cytokinin was the most effective at promoting germination in orchid "green pod cultures" $[51,52]$. In addition, [53] reported that a combination of IBA and BA improved protocorm recovery from endangered orchid of the genus Orchis and stimulated protocorm formation in Serapias vomeracea [54]. The early development of Dactylorhiza species seedlings was also enhanced by a combination of cytokinin $2 \mathrm{iP}$ with auxin [55]. Similar to these findings, our data confirmed the benefit of PGRs addition only at the initial stages of $O$. militaris seed germination, while the most favorable medium for protocorm enlargement and seedling development was $\mathrm{mM}+\mathrm{OA}$ medium without PGRs, but supplemented with CW and BS.

We also detected the promotional effect of $\mathrm{AC}$ on $O$. militaris morphogenesis, which may be due to its adsorption of inhibitory phenolic compounds, often observed during the development of protocorms [56]. Thus, the subculture in the $\mathrm{mKC}$ with the addition of $\mathrm{AC}$ could be necessary to stimulate the development of protocorms. We suppose that AC was not necessary during the early ( $\mathrm{S} 1$ and S2) stages of seed germination but could play an important role in $O$. militaris seedling development toward rhizogenesis, as has been reported for another orchid species [57]. Our results showed that, even in the absence of auxin, root development occurred in shoots grown on $\mathrm{mM}$ medium containing AC. Thus, $\mathrm{mM}+\mathrm{OA}$, which combined $\mathrm{AC}$ and complex OA, was found to be the most suitable medium for the formation of $O$. militaris plantlets from protocorms.

\section{Conclusion}

Optimization of different temperature and light regimes for the in vitro germination and culture of $O$. militaris, comparable to seasonal temperature changes and dormant periods which the species endured under the natural conditions, was performed. Seeds cultured under 0/ 24-h light/dark photoperiod were capable of evolving through subsequent development stages, when protocorms could grow to over $2 \mathrm{~cm}$ in height following 2 months of culture on mHar2 sowing medium supplemented with $4.92 \mu \mathrm{M} 2 \mathrm{iP}+1.61 \mu \mathrm{M}$ IBA, followed by $\mathrm{mKC}$, supplemented with $0.1 \% \mathrm{AC}$ and then by Malmgren modified medium, enriched by $5 \% \mathrm{CW}, 5 \% \mathrm{BS}$, and $0.1 \%$ AC. O. militaris protocorms maintained on $\mathrm{mM} \pm$ OA medium successfully progressed toward the advanced seedling stage (stage 6) within 12 months. Hence, this efficient procedure for regenerating protocorms and seedlings from immature seeds of $O$. militaris could be used for commercial exploitation and ex situ conservation of this valuable endangered terrestrial orchid species.

\section{Abbreviations \\ BA: 6-Benzylaminopurine; IBA: Indole butyric acid; 2iP: 2-Isopentenyladenine; mHar: Harvais medium; mKC: Knudson C medium; mM: Malmgren medium; PGRs: Plant growth regulators; OA: Organic additives; PH: Potato homogenate; AC: Activated charcoal; CW: Coconut water; BS: Birch sap}

\section{Acknowledgements}

The author is grateful to assistant professor Dr. Doronkin VM, Central Siberian Botanical Garden, SB RAS, for the identification of Orchis militaris L. The author thanks the anonymous reviewers for their careful reading of the manuscript and their insightful comments and suggestions. The obtained in vitro plantlets are included in the collection of the Central Siberian Botanical Garden SB RAS - USU 440534 "Collection of living plants indoors and outdoors". The work was carried out with the financial support of the budgetary project of the Central Siberian Botanical Garden, SB RAS № AAAAA21- 121011290025-2 within the framework of the State Assignment.

\section{Author's contributions}

AYuN proposed the research idea, collected seeds, designed and performed all the experiments in vitro, analyzed the data, prepared, and approved the final manuscript.

Funding

Not applicable.

Availability of data and materials Not applicable.

\section{Declarations}

Ethics approval and consent to participate Not applicable.

Consent for publication

Not applicable. 


\section{Competing interests}

The author declares that she has no competing interests.

Received: 13 April 2021 Accepted: 16 July 2021

Published online: 19 August 2021

\section{References}

1. Kretzschmar H, Eccarius W, Dietrich H (2007) The orchid genera Anacamptis. Phylogeny, taxonomy, morphology, biology, distribution, ecology and hybridization. Echinomedia, Bürgel, Orchis and Neotinea

2. Govaerts R, Bernet P, Kratochvil K, Gerlach G, Carr G, Alrich P, Pridgeon AM, Pfahl J, Campacci MA, Baptista HD, Tigges H, Shaw J, Cribb PJ, George A, Kreuz K, Wood J (2016) World Checklist of Orchidaceae. Royal Botanic Gardens, Kew, London. Available at http://apps.kew.org/wcsp/

3. Kreziou A, De Boer H, Gravendeel B (2016) Harvesting of salep orchids in north-western Greece continues to threaten natural populations. Oryx 50(3): 393-396. https://doi.org/10.1017/S0030605315000265

4. Jagdale SP, Shimpi S, Chachad D (2009) Pharmacological studies of 'Salep'. J. Herb Med Toxic 3(1):153-156

5. Ghorbani A, Gravendeel B, Naghibi F, de Boer HJ (2014) Wild orchid tuber collection in Iran: a wake-up call for conservation. Biodivers Conserv 23: 2749-2760.

6. Seaton P, Ramsay M (2005) Growing orchids from seed. Royal Botanic Gardens, Kew, London

7. Jakobsone G (2008) Morphogenesis of wild orchid Dactylorhiza fuchsii in tissue culture. Acta Univer Latv, Biology 745:17-23

8. Valletta A, Attorre F, Bruno F, Pasqua G (2008) In vitro asymbiotic germination of Orchis mascula L. Plant Biosyst 142(3):65655. https://doi.org/1 0.1080/11263500802411205

9. Bektas E, Cuce M, Sokmen A (2013) In vitro germination, protocorm formation, and plantlet development of Orchis coriophora (Orchidaceae), a naturally growing orchid species in Turkey. Turk J Bot 37(2):336-342

10. Farrell L (1985) Biological flora of the British Isles: Orchis militaris L. J Ecol 73: 1041-1053

11. Evans A, Janssens S, Jacquemyn $H$ (2020) Impact of climate change on the distribution of four closely related Orchis (Orchidaceae) species. Diversity 12(8), 312. https://doi.org/10.3390/d12080312.

12. Averyanov LV (2008) Orchis militaris L. In: Bardunov LV, Novikov VS (eds) The Red Data Book of the Russian Federation (Plants and Fungi). KMK Scientific Press Ltd., Moscow

13. Calevo J, Voyron S, Ercole E, Girlanda M (2020) Is the distribution of two rare Orchis sister species limited by their main mycobiont? Diversity 12(262). https://doi.org/10.3390/d12070262

14. Fardeeva MB (2007) Ontogeny of Orchis militaris L. In: Ontogenetic Atlas of Plants. 5:238-241. Mari. Gos. Univ, Yoshkar Ola.

15. Tremblay RL, Ackerman JD, Zimmerman JK, Calvo RN (2005) Variation in sexual reproduction in orchids and its evolutionary consequences: a spasmodic journey to diversification. Biol J Linn Soc 84:1-54. https://doi. org/10.1111/j.1095-8312.2004.00400.x

16. Henneresse T, Wesselingh RA, Tyteca D (2017) Effects of floral display, conspecific density and rewarding species on fruit set in the deceptive orchid Orchis militaris (Orchidaceae). Plant Ecol. Evol 150:279-292. doi.org/ https://doi.org/10.5091/plecevo.2017.1313.

17. Vakhrameeva MG, Varlygina TI, Tatarenko IV (2014) Orchids of Russia (biology, ecology and protection). KMK Scientific Press, Moscow

18. Pierce S, Cerabolini BEL (2011) Asymbiotic germination of the White Mountain Orchid (Pseudorchis albida) from immature seed on media enriched with complex organics or phytohormones. Seed Sci Technol 39(1): 199-203. https://doi.org/10.15258/sst.2011.39.1.17

19. Kendon JP, Rajaovelona L, Sandford H, Fang R, Bell J, Sarasan V (2017) Collecting near mature and immature orchid seeds for ex situ conservation: 'in vitro collecting' as a case study. Bot Stud. 58(1):34. https://doi.org/10.11 86/s40529-017-0187-5

20. Krasnoborov IM (2000) Determinant of plants of the Novosibirsk region. Nauka, Novosibirsk

21. Harvais G (1973) Growth requirements and development of Cypripedium reginae in axenic culture. Canad J Bot 51(2):327-332

22. Swarts ND, Dixon KW (2017) Conservation methods for terrestrial orchids. J. Ross Publishing, United States

23. Knudson L (1946) A nutrient for germination of orchid seeds. Am Orchid Soc Bull 15:214-217
24. Malmgren S (1996) Orchid propagation: theory and practice. In: Allen C (ed) Proceedings of North American native terrestrial orchid conference, Maryland.

25. Rasmussen HN (1995) Terrestrial orchids: From seed to mycotrophic plant. Cambridge University Press, Cambridge

26. Malmgren S, Nyström H (2011) Orchid Propagation. http://www.lidaforsga rden.com/Orchids/engelsk.htm

27. Kulikov PV, Phillippov EG (1998) On propagation of temperate zone orchids by tissue culture methods. Bulletin of the Main botanical garden of Russian Academy of Science 176:125-131

28. Metsare M, Ilves A, Haldna H, Kull T, Tali K (2015) Four seed-quality measures in orchids with different pollination systems. Acta Bot Gallica 162(4):263269. https://doi.org/10.1080/12538078.2015.1100549

29. Ye Z-M, Dai W-K, Jin X-F, Gituru RW, Wang Q-F, Yang C-F (2014) Competition and facilitation among plants for pollination: can pollinator abundance shift the plant-plant interactions? Plant Ecol 215:3-13. https:// doi.org/10.1007/s1 1258-013-0274-y

30. Yeung EC (2017) A perspective on orchid seed and protocorm development. Bot Stud. 58(1):33. https://doi.org/10.1186/s40529-017-0188-4

31. Hürkan YK, Hürkan K, Aki C (2018) Comparative growth media performances on in vitro propagation of some salep orchids. Anadolu University Journal of Science and Technology - C Life Sciences and Biotechnology 7(1):52-62

32. Baskin CC, Thompson K, Baskin JM (2006) Mistakes in germination ecology and how to avoid them. Seed Sci Res 16:165-168

33. Delforge P (2006) Orchids of Europe, North Africa and the Middle East, 3rd edn. A \& C Black, London

34. Calevo J, Bazzicalupo M (2020) Less is more: low-cost in vitro . Nat Conserv Res 5(1):172-177. https://doi.org/10.24189/ncr.2020.043

35. Arditti J. (ed) (1981). Orchid Biology. Reviews and perspectives. Orchid seed germination and seedling culture, vol 11. Cornell University Press, Ithaca, New York

36. Teixeira da Silva JA (2013) Orchids: Advances in tissue culture, genetics, phytochemistry and transgenic biotechnology. Floricult Ornam Biotech 7:1-52

37. Yamazaki J, Miyoshi K (2006) In vitro asymbiotic germination of immature seed and formation of protocorm by Cephalanthera falcata (Orchidaceae). Ann Bot 98(6):1197-1206. https://doi.org/10.1093/aob/mcl223

38. Yeung EC, Li YY, Lee YI (2018) Understanding seed and protocorm development in orchids. In: Lee YY, Yeung EC (eds) Orchid Propagation: from laboratories to greenhouses - methods and protocols. Springer Protocols Handbooks, New York, pp 1-24

39. Huh YS, Lee JK, Nam SY, Paek KY, Suh GU (2016) Improvement of asymbiotic seed germination and seedling development of Cypripedium macranthos Sw. with organic additives. J Plant Biotechnol 43(1):138-145

40. Burch RM, Chambers CB (2013). Micropropagation and establishment of Cypripedium 'Lady slipper' orchids. Acta Hortic 988:161-166 https://doi. org/10.17660/ActaHortic.2013.988.18

41. Tawaro S, Suraninpong P, Chanprame S (2008) Germination and regeneration of Cymbidium findlay sonianum Lindl. on a medium supplemented with some organic sources. Walailak J Sci Tech 5:125-135

42. Tan S, Yong J, Ge L (2014) Analyses of phytohormones in coconut (Cocos nucifera $\mathrm{L}$.) water using capillary electrophoresis-tandem mass spectrometry. Chromatography 1(4):211-226

43. Kefeli V, Kalevitch MV (2003) Natural growth inhibitors and phytohormones in plants and environment. In: Borsari B (ed) Kluwer Academic Publishers, Dordrech, p.324.

44. Molnar Z, Virag E, Ordog E (2011) Natural substances in tissue culture media of higher plants. Acta Biol Szegedvol 55(1):123-127

45. Pakum W, Watthana S, Srimuang KO, Kongbangkerd A (2016) Influence of medium component on in vitro propagation of Thai's endangered orchid: Bulbophyllum nipondii Seidenf. Plant Tissue Cult Biotechnol 26(1): $37-46$.

46. Zhang Y, Lee YI, Deng L, Zhao S (2013) Asymbiotic germination of immature seeds and seedling development of Cypripedium macranthos SW. , an endangered Lady's slipper orchid. Sci Hortic 164:130-136

47. Novak SD, Luna L, Gamage RN (2014) Role of auxin in orchid development. Plant Signal Behav 9(10):e972277. https://doi.org/10.4161/psb.32169

48. Ponert J, Vosolsobě S, Kmecová K, Lipavská H (2011) European orchid cultivation - from seed to mature plant. Eur J Environ Sci 1(2):95-107

49. De KK, Majumdar S, Sharma R, Sharma B (2006) Green pod culture and rapid micropropagation of Dendrobium chrysanthum Wall. - a horticultural and medicinal orchid. Folia Hortic 18:81-90 
50. Godo T, Komori M, Nakaoki E, Yukawa T, Miyoshi K (2010) Germination of mature seeds of Calanthe tricarinata Lindl., an endangered terrestrial orchid, by asymbiotic culture in vitro. In Vitro Cell Dev Biol - Plant 46:323-328

51. Baker A, Kaviani B, Nematzadeh G, Negahdar N (2014) Micropropagation of Orchis catasetum - a rare and endangered orchid. Acta Sci Pol, Hortorum Cultus 13:197-205

52. Bektas E, Sokmen A (2016) In vitro seed germination, plantlet growth, tuberization, and synthetic seed production of Serapias vomeracea (Burm.f.) Briq. Turk J Bot 40:584-594 https://doi.org/10.3906/bot-1512-13

53. Novotna KW, Vejsadova H, Kindlmann P (2007) Effects of sugars and growth regulators on in vitro growth of Dactylorhiza species. Biol Plantarum 51:198200

54. Gutierrez-Sanchez A, Monriboc-Villanueva JL, Cocotle-Ronzón Y, MartinezCruz NS, Guerrero-Analco JA (2020) Phenolic profile and antioxidant activity from wild and in vitro cultivated Rhynchostele rossii (Orchidaceae). Acta Bot Mex 127(127), e1665. https://doi.org/10.21829/abm127.2020.1665

55. Vudala SM, Ribas LLF (2017) Seed storage and asymbiotic germination of Hadrolaelia grandis (Orchidaceae). S Afr J Bot 108:1-7. https://doi.org/10.101 6/j.sajb.2016.09.008

56. Merritt DJ, Hay FR, Swarts ND, Sommerville KD, Dixon KW (2014) Ex situ conservation and cryopreservation of orchid germplasm. Int J Plant Sci 175(1):46-58

57. Vujanovic V, St-Arnaud M, Barabe D, Thibeault G (2000) Viability testing of orchid seed and the promotion of colouration and germination. Ann Bot 86(1):79-86

\section{Publisher's Note}

Springer Nature remains neutral with regard to jurisdictional claims in published maps and institutional affiliations.

\section{Submit your manuscript to a SpringerOpen ${ }^{\circ}$ journal and benefit from:}

- Convenient online submission

- Rigorous peer review

- Open access: articles freely available online

- High visibility within the field

- Retaining the copyright to your article

Submit your next manuscript at $\boldsymbol{\nabla}$ springeropen.com 